\title{
Managing liver cirrhotic complications: Overview of esophageal and gastric varices
}

\author{
Cosmas Rinaldi Adithya Lesmana, ${ }^{1,2}$, Monica Raharjo', and Rino A. Gani' \\ 'Division of Hepatobiliary, Department of Internal Medicine, Dr. Cipto Mangunkusumo National General Hospital, Medical Faculty \\ Universitas Indonesia, Jakarta; ${ }^{2}$ Digestive Disease \& GI Oncology Centre, Medistra Hospital, Jakarta, Indonesia
}

Managing liver cirrhosis in clinical practice is still a challenging problem as its progression is associated with serious complications, such as variceal bleeding that may increase mortality. Portal hypertension (PH) is the main key for the development of liver cirrhosis complications. Portal pressure above $10 \mathrm{mmHg}$, termed as clinically significant portal hypertension, is associated with formation of varices; meanwhile, portal pressure above $12 \mathrm{mmHg}$ is associated with variceal bleeding. Hepatic vein pressure gradient measurement and esophagogastroduodenoscopy remain the gold standard for assessing portal pressure and detecting varices. Recently, non-invasive methods have been studied for evaluation of portal pressure and varices detection in liver cirrhotic patients. Various guidelines have been published for clinicians' guidance in the management of esophagogastric varices which aims to prevent development of varices, acute variceal bleeding, and variceal rebleeding. This writing provides a comprehensive review on development of $\mathrm{PH}$ and varices in liver cirrhosis patients and its management based on current international guidelines and real experience in Indonesia. (Clin Mol Hepatol 2020;26:444-460)

Keywords: Liver cirrhosis; Hypertension, Portal; Esophageal and gastric varices

\section{INTRODUCTION}

Liver cirrhosis $(L C)$ is still a challenging problem in clinical practice as it comprises many complications due to portal hypertension $(\mathrm{PH})$, such as the presence of varices, variceal bleeding, asci- tes, hepatic encephalopathy, coagulation dysfunction, hepatorenal syndrome, and even cardiac and pulmonary complications. It has been defined as a liver condition characterized by liver scar tissue or tissue fibrosis and the conversion of normal liver architecture into abnormal nodules due to long-term inflammation process of

\footnotetext{
Abbreviations:

AASLD, the American Association for the Study of Liver Diseases; APASL, the Asian Pacific Association for the Study of the Liver; AVB, acute variceal bleeding; BRTO, balloon-occluded retrograde transvenous obliteration; $\mathrm{Cl}$, confidence interval; CP, Child-Pugh; CSPH, clinically significant portal hypertension; EASL, the European Association for the Study of the Liver; EGD, esophagogastroduodenoscopy; EGV, esophagogastric varices; EUS, endoscopic ultrasound; EV, esophageal varices; EVL, endoscopic variceal ligation; EVO, endoscopic variceal obturation; GOV, gastroesophageal varices; GOV1, type 1 gastroesophageal varices; GOV2, type 2 gastroesophageal varices; GV, gastric varices; HCC, hepatocellular carcinoma; HR, hazard ratio; HVPG, hepatic vein pressure gradient; IGV, isolated gastric varices; IGV1, type 1 isolated gastric varices; IGV2, type 2 isolated gastric varices; IL, interleukin; KASL, the Korean Association for the Study of the Liver; LC, liver cirrhosis; NSBB, non-selective beta blocker; OR, odds ratio; $\mathrm{PH}$, portal hypertension; $\mathrm{RCT}$, randomized controlled trial; $R R$, relative risk; $T E$, transient elastography; TIPS, transjugular intrahepatic portosystemic shunt
}

Corresponding author : Cosmas Rinaldi Adithya Lesmana Division of Hepatobiliary, Department of Internal Medicine, Dr. Cipto Mangunkusumo National General Hospital, Jalan Diponegoro No. 71, Central Jakarta 10430, Indonesia

Tel: +62 8129060 1045, Fax: + 62131900924

E-mail:medicaldr2001id@yahoo.com

https://orcid.org/0000-0002-8218-5971 
Cosmas Rinaldi Adithya Lesmana, et al.

chronic liver diseases. ' Common etiologies of LC are chronic hepatitis B and C virus infection, alcoholic liver disease, non-alcoholic fatty liver disease, autoimmune liver disease, and drug induced liver injury. Hepatitis virus infection, alcohol-related liver disease, and non-alcoholic steatohepatitis are common causes of cirrhosis deaths globally. ${ }^{2,3}$ Acute variceal bleeding (AVB) is a complication of $\mathrm{LC}$ considered to be the most feared due to its high mortality, especially in the presence of gastric varices (GV). Therefore, we would like to review guidelines and real experiences on managing LC complications, focusing on esophageal varices (EV) and GV.

\section{NATURAL HISTORY AND COMPLICATIONS OF LC}

The Global Burden of Disease 2017 Study reported 1.32 million (1.27 to 1.45 million) deaths in 2017 due to $L C$ which constituted $2.4 \%$ of total deaths globally in 2017. ${ }^{3}$ These numbers have increased from the previous Global Burden of Disease 2010 Study which reported 1.02 million $(670,216$ to 1.55 million) deaths, constituting $1.9 \%$ of all deaths globally, in $2010{ }^{2}$

LC can be considered as the end-stage of every chronic liver disease. The course of LC can be divided into an asymptomatic phase termed compensated cirrhosis and a phase where complications, such as variceal bleeding, develop termed decompensated cirrhosis. Transition of compensated cirrhosis to decompensated cirrhosis occurs at a rate of approximately $5-7 \%$ every year. As $\mathrm{LC}$ progresses, other complications may arise. At any phase of $\mathrm{LC}$, hepatocellular carcinoma (HCC) may develop and accelerate course of the disease leading to a worse outcome. The rate of HCC development is approximately $3 \%$ per year. ${ }^{4}$ As there is no clear definition to differentiate between severe fibrosis and compensated cirrhosis, the Baveno VI consensus recommends that this transition phase be termed compensated advanced chronic liver disease. Both terms, compensated advanced chronic liver disease and compensated cirrhosis, can be used interchangeably. ${ }^{5}$

The survival of patients with compensated $L C$ is significantly longer than patients with decompensated LC. Median survival times were estimated to be around 12 years in compensated $\mathrm{LC}$ patients and around 2 years in decompensated LC patients. A cohort study reported that median survival time of compensated LC patients was 9.5 years and that of decompensated LC patients was 4.5 years. Median time to decompensation was 5 years. Variceal bleeding is one of the most commonly reported causes of death in LC patients. Age, Child-Pugh (CP) score and its compo- nents, model for end-stage liver disease score, hepatic vein pressure gradient (HVPG), and presence of HCC were independent predictors of death in patients with $\mathrm{LC}^{4,6}$

\section{DEVELOPMENT OF PH}

Persistent inflammation in chronic liver injury leads to two conditions: fibrogenesis and pathological angiogenesis. Fibrogenesis is actually part of the liver's healing response to injury. Damaged hepatocytes in liver injury release inflammatory mediators, recruiting leukocytes to site of injury which releases pro-inflammatory mediators such as cytokines (tumour necrosis factor, interleukin [IL]-6, and IL-1 $\beta$ ), metalloproteinases, platelet-derived growth factor, connective tissue growth factor, transforming growth factor- $\beta$, fibroblast growth factor, and vascular endothelial growth factor. These cytokines and growth factors are involved in fibrogenesis and angiogenesis. Hepatic stellate cells which differentiate into myofibroblasts, mediated by cytokines and growth factors, produces liver scar tissue high in type I collagen which protects hepatocytes against further injury. However, accumulation of tissue fibrosis leads to tissue stiffness.

Another mechanism, i.e., progressive liver tissue hypoxia, also induces liver fibrogenesis and angiogenesis. Liver angiogenesis is closely related to the progression of liver fibrosis. Accumulation of inflammatory cells and tissue fibrosis increases resistance of the damaged cells to blood flow and oxygen supply, hence contributing to hypoxia. As a response to hypoxia, hepatic stellate cells release vascular endothelial growth factor and angiopoietin-1 which induce angiogenesis. Hypoxia also stimulates further inflammation leading to further fibrosis. ${ }^{8}$

Structural hepatic changes due to tissue fibrosis and changes in hepatic microcirculation due to pathological angiogenesis increase intrahepatic vascular resistance. This phenomenon increases portal pressure and leads to PH in LC. Other factors contributing to increased intrahepatic vascular resistance include decreased hepatic production and/or bioavailability of nitric oxide, a potent vasodilator, and increased hepatic production of vasoconstrictors, such as thromboxane A2. This condition leads to intrahepatic vasoconstriction. ${ }^{9,10}$

$\mathrm{PH}$ is defined as an increase in the pressure of the portal vein and its branches. ${ }^{10}$ Portal pressure can be measured accurately through direct and indirect measurement. Direct measurement of portal pressure is no longer performed due to its high invasiveness. HVPG measurement, an indirect measure of portal pressure, 


\section{CLINCAL and MOLECULAR
HEPATOLOGY}

Volume_26 Number_4 October 2020

is now considered as a gold standard tool to measure portal pressure. HVPG is the gradient between the portal vein and the hepatic vein calculated by subtracting free hepatic venous pressure from wedge hepatic venous pressure. $\mathrm{PH}$ is diagnosed when HVPG is above $5 \mathrm{mmHg}$, whereas clinically significant PH (CSPH) is diagnosed when HVPG is above $10 \mathrm{mmHg}$ (Table 1). This measurement is very important in managing $\mathrm{LC}$ patients because complications of PH begin to appear when CSPH is diagnosed. ${ }^{11,12}$ There have been several non-invasive and minimally invasive tools developed in clinical practice to replace the use of HVPG, such as doppler ultrasound, contrast-enhanced ultrasound, and transient elastography (TE)/Fibroscan ${ }^{\circledR}$. However, studies on doppler ultrasound did not show high sensitivity for detection of CSPH even though it showed high specificity..$^{13}$ Meanwhile, study on contrastenhanced ultrasound in assessing hepatic vein arrival time to predict CSPH in patients with compensated cirrhosis showed that there have been major concerns regarding its use in clinical practice due to high failure rate, poor echo window in patients with obesity, respiratory disturbances, or atrophic right liver lobe. ${ }^{14} \mathrm{TE}$ has been considered as the simplest and easiest tool to be used in daily practice. Bureau et al found that HVPG was correlated with liver stiffness measurement by TE $(P<0.001)$ and the cut-off value of $21 \mathrm{kPa}$ accurately predicted CSPH in patients with chronic liver disease. ${ }^{15}$ The Baveno VI consensus workshop recommends that liver stiffness measurement by TE $\geq 20-25 \mathrm{kPa}$ alone or combined with platelet count and spleen size may be used to rule-in CSPH

Table 1. Correlation of portal pressure and clinical end-points in patients with liver cirrhosis

\begin{tabular}{|c|c|}
\hline Portal pressure & Clinical end-points \\
\hline$<5 \mathrm{mmHg}$ & Normal \\
\hline $5-10 \mathrm{mmHg}$ & Mild portal hypertension \\
\hline$>10 \mathrm{mmHg}$ & Clinically significant portal hypertension \\
\hline$>10 \mathrm{mmHg}$ & Esophageal varices development, ascites, decompensation, hepatocellular carcinoma occurrence \\
\hline$>12 \mathrm{mmHg}$ & Variceal bleeding \\
\hline$>16 \mathrm{mmHg}$ & High mortality \\
\hline$>20 \mathrm{mmHg}$ & Early rebleeding or failure to control bleeding \\
\hline
\end{tabular}

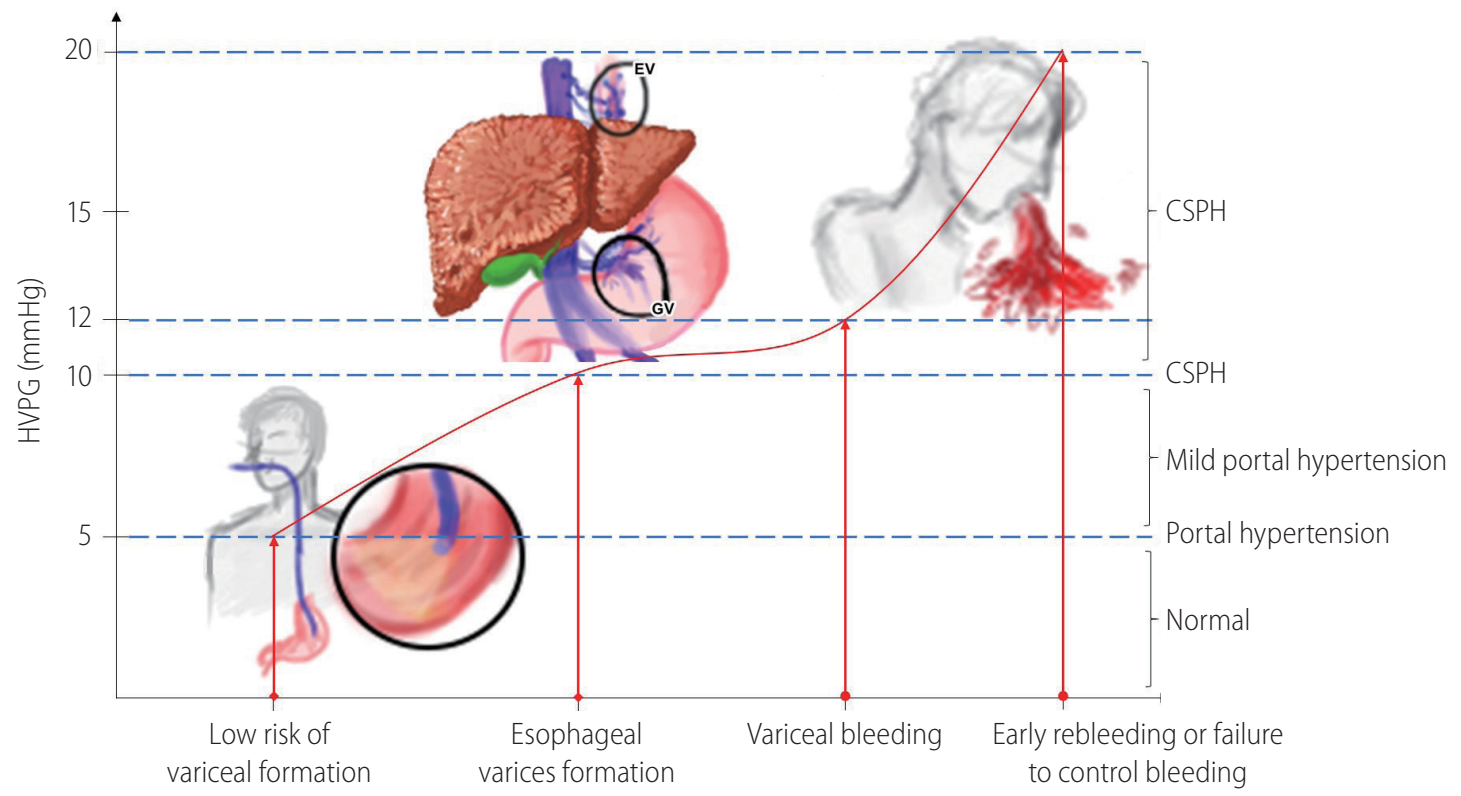

Risk of varices development associated with increased HVPG

Figure 1. Relationship of portal hypertension and risk of varices development. HVPG, hepatic vein pressure gradient; EV, esophageal varices; GV, gastric varices; CSPH, clinically significant portal hypertension. 


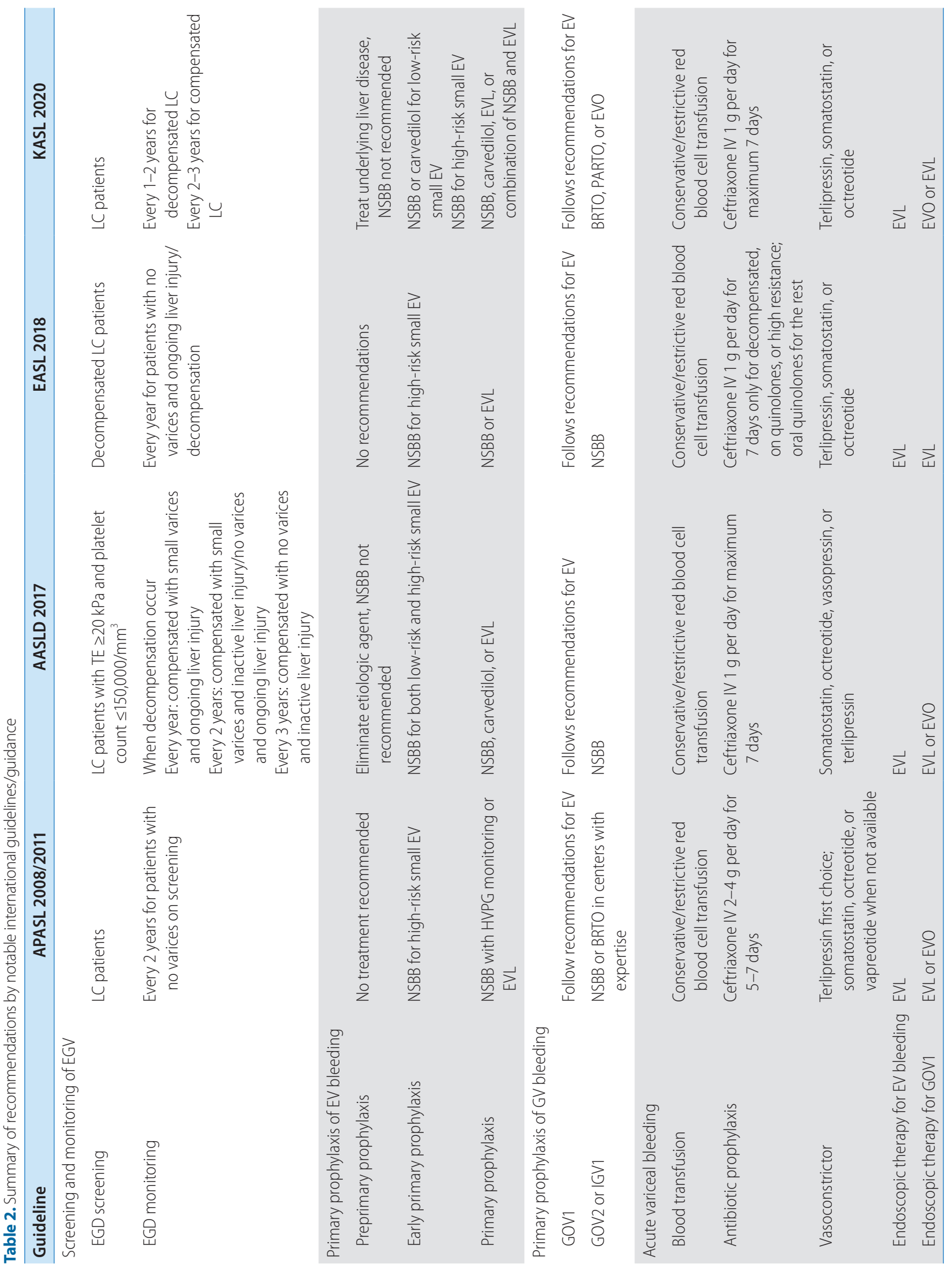




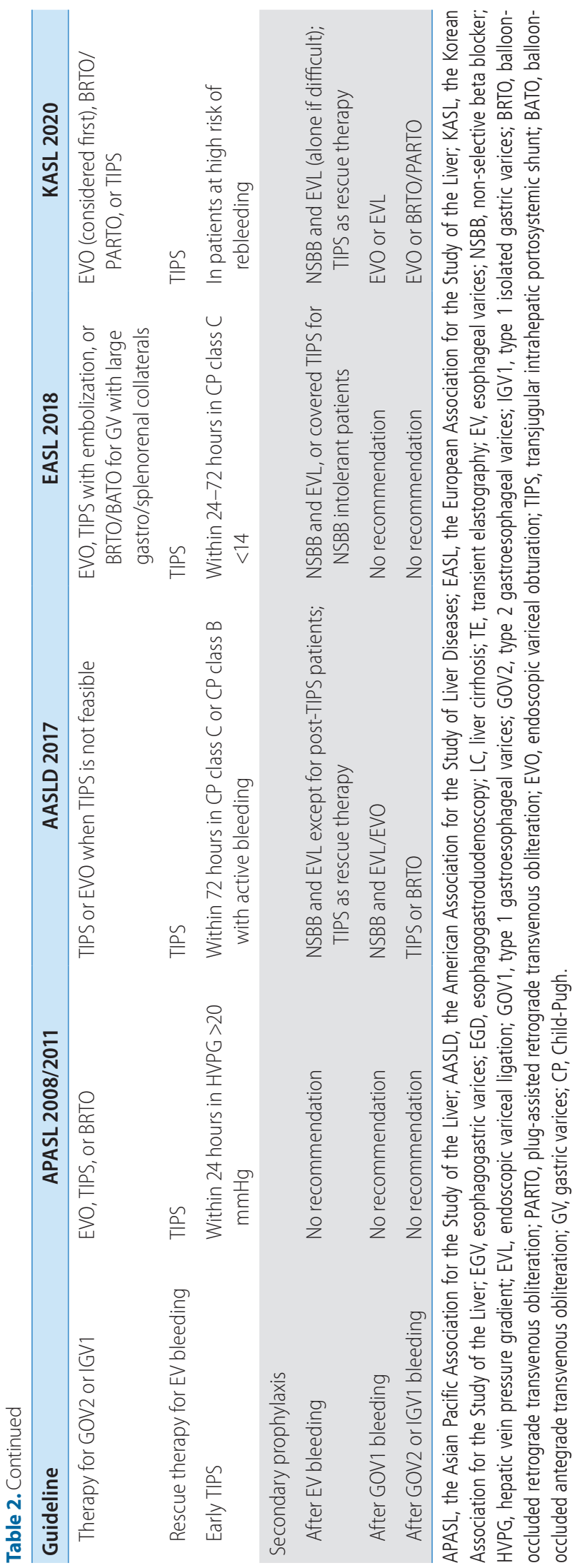

in patients with viral $\mathrm{LC}^{5}$

\section{DEVELOPMENT OF ESOPHAGOGASTRIC VARI- CES (EGV)}

EV and GV are complications of PH present in approximately $50 \%$ and $20 \%$ of patients with LC, respectively. ${ }^{10,16} \mathrm{EV}$ was first described by Richard Schatzki, a renowned radiologist, in 1940 as "dilated veins that bulge into the lumen, producing uneven wormlike surface of the inside of esophagus". 17,18 Varices develop when HVPG is above $10 \mathrm{mmHg}$ and variceal bleeding potentially occurs when HVPG is above $12 \mathrm{mmHg}$ (Table 1, Fig. 1).11,16

Varices usually arise at a rate of $7-8 \%$ every year and progress from small to large varices at a rate of $10-12 \%$ every year. ${ }^{19}$ Increase in portal pressure stimulates the release of angiogenic factors such as vascular endothelial growth factor and placental growth factor from the vascular beds of the splanchnic circulation, which promotes angiogenesis leading to formation of portosystemic collaterals. Portosystemic collaterals also formed by the opening, dilatation, and hypertrophy of existing blood vessels in the setting of increased portal pressure. As a result, blood from the splanchnic circulation is diverted into the collateral circulation, stimulating compensatory mechanisms known as splanchnic vasodilatation. The aforementioned compensatory mechanisms include increased production of the nitric oxide vasodilator in the splanchnic circulation, decreased contractility of arteries in the splanchnic circulation, and sympathetic nerve atrophy/regression in arteries of the splanchnic circulation; all of it causes increased blood flow into the portal vein, which further increases portal pressure and leads to the development of portosystemic collaterals. ${ }^{9,16}$ Portosystemic collaterals of the anterior branch of left gastric vein, which dilates more than $7 \mathrm{~mm}$ in the presence of $\mathrm{PH}$, cause dilation of veins located within the lower esophageal wall termed EV. Meanwhile, GV arises from portosystemic collaterals of the anterior branch of the left gastric vein, short gastric vein, or posterior gastric vein. ${ }^{20}$

LC patients also have a hyperdynamic circulation defined as high blood volume/high cardiac output but low effective blood volume due to low systemic vascular resistance caused by systemic vasodilatation. This hyperdynamic circulation further aggravates PH and variceal development. ${ }^{21}$

AVB occurs in $16-75.6 \%$ of patients not previously treated for EV and $25 \%$ of patients not previously treated for GV. Isolated gastric varices (IGV) is the most severe and is associated with the 
highest mortality rate compared to variceal bleeding due to EV or gastroesophageal varices (GOV). Risk factors for EV bleeding include varices located in critical area (EV bleeding commonly occurs at $3 \mathrm{~cm}$ proximal to the gastroesophageal junction), high portal pressure (decreasing HVPG to $12 \mathrm{mmHg}$ or less lowers the risk of variceal bleeding), large size varices, blue coloration, and the presence of red-color signs. ${ }^{22} \mathrm{GV}$, on the other hand, can be present in the setting of lower portal pressure compared to EV. Large size varices (more than $5 \mathrm{~mm}$ in diameter), red-color signs, and advanced stage of liver disease (CP class B or C) are considered as the most important risk factors for GV bleeding. Other risk factors for GV bleeding are mucosal erosions and/or gastric ulcers over varices and use of oral non-steroidal anti inflammatory drugs. ${ }^{22,23}$

\section{MANAGEMENT OF EGV: CURRENT GUIDELINES AND RECENT UPDATES}

Various clinical practice guidelines and guidance have been published on the management of EGV with recommendations regarding prevention and management of variceal bleeding. In this review, we will address three guidelines and one guidance put forward by four notable hepatology societies, i.e., the American Association for the Study of Liver Diseases (AASLD) ${ }_{1}^{24}$ the Asian Pacific Association for the Study of the Liver (APASL), ${ }^{25,26}$ the European Association for the Study of the Liver (EASL), ${ }_{1}^{27}$ and the Korean Association for the Study of the Liver (KASL) ${ }^{28}$ (Table 2). The most recent of these is the clinical practice guidelines by KASL published earlier this year.

\section{Screening and monitoring of EGV}

Until today, esophagogastroduodenoscopy (EGD) has been considered as the gold standard for diagnosis and screening of varices in patients with $L C$. AASLD recommends EGD screening for diagnosis of varices in patients with TE of $\geq 20 \mathrm{kPa}$ and platelet count $\leq 150,000 / \mathrm{mm}^{3}$ when the diagnosis of cirrhosis is made. ${ }^{24}$ Meanwhile, EASL recommends EGD screening for all decompensated cirrhosis patients, APASL and KASL for all diagnosed LC patients. ${ }^{25,27,28}$ Based on EGD procedure, varices can be uniformly described according to the general rules for recording endoscopic findings of EGV proposed by the Japan Society for Portal Hypertension (Table 3). ${ }^{29} \mathrm{EASL}$, APASL, and KASL recommend recording the presence and size of EGV and the presence of red-color signs. $^{25,27,28}$
Classification for EV has been developed since 1964 by Brick and Palmer, ${ }^{30}$ since then many classifications have been proposed such as Dagradi classification, Soehendra classification, Conn's classification, Paquet's classification, Westaby classification, and Calès classification. ${ }^{18}$ However, in clinical practice, EV can be simply classified as high risk or low risk. High-risk EV has higher risk of bleeding and is associated with higher mortality. Low-risk EV is defined as small varices $(\leq 5 \mathrm{~mm})$ without red-color signs; meanwhile, high-risk EV is defined as medium-large varices ( $>5 \mathrm{~mm})$, small varices with red-color signs, or small varices in patients with CP class C (Table 4). ${ }^{27}$ Red-color signs are reddish changes be-

Table 3. General rules for recording endoscopic findings of esophagogastric varices by the Japan Society for Portal Hypertension

\begin{tabular}{|c|c|}
\hline Category & Endoscopic finding \\
\hline Location & $\begin{array}{l}\text { Ls: Locus superior } \\
\text { Lm: Locus medialis } \\
\text { Li: Locus inferior } \\
\text { Lg-c: Adjacent to the cardiac orifice } \\
\text { Lg-cf: Extension from the cardiac orifice to } \\
\text { the fornix } \\
\text { Lg-f: Isolated in the fornix } \\
\text { Lg-b: Located in the gastric body } \\
\text { Lg-a: Located in the gastric antrum }\end{array}$ \\
\hline Form & $\begin{array}{l}\text { F0: No varicose appearance } \\
\text { F1: Straight, small-caliber varices } \\
\text { F2: Moderately enlarged, beady varices } \\
\text { F3: Markedly enlarged, nodular or tumor- } \\
\text { shaped varices }\end{array}$ \\
\hline Color & $\begin{array}{l}\text { Cw: White varices } \\
\text { Cb: Blue varices } \\
\text { Cw-Th: Thrombosed white varices } \\
\text { Cb-Th: Thrombosed blue varices }\end{array}$ \\
\hline Red-color signs & $\begin{array}{l}\text { RWM: Red wale markings } \\
\text { CRS: Cherry red spots } \\
\text { HCS: Hematocystic spots } \\
\text { Te: Telangiectasia }\end{array}$ \\
\hline Bleeding signs & $\begin{array}{l}\text { Gushing bleeding } \\
\text { Spurting bleeding } \\
\text { Oozing bleeding } \\
\text { Red plug } \\
\text { White plug }\end{array}$ \\
\hline Mucosal findings & $\begin{array}{l}\text { E: Erosion } \\
\text { Ul: Ulcer } \\
\text { S: Scar }\end{array}$ \\
\hline $\begin{array}{l}\text { Portal hypertensive } \\
\text { gastropathy }\end{array}$ & $\begin{array}{l}\text { Snakeskin/mosaic appearance with: } \\
\text { Grade 1: Erythematous flecks or maculae } \\
\text { Grade 2: Red spots and/or diffuse redness } \\
\text { Grade 3: Intramucosal or intraluminal } \\
\text { hemorrhage }\end{array}$ \\
\hline
\end{tabular}




\section{HEPATOLOGY}

Volume_26 Number_4 October 2020

neath the esophageal submucosa classified into red wale markings, cherry-red spots, and hematocytic spots (Fig. 2). Red wale

Table 4. Classification of esophageal varices

\begin{tabular}{|c|c|}
\hline & Classification \\
\hline Low-risk varices & Small varices without red-color signs \\
\hline High-risk varices & $\begin{array}{l}\text { Medium-large varices } \\
\text { Small varices with red-color signs } \\
\text { Small varices in Child-Pugh class C cirrhotic } \\
\text { patients }\end{array}$ \\
\hline
\end{tabular}

markings are wale or whip marks oriented longitudinally on the surface of EV. Cherry-red spots are small red spots on the surface of EV. Hematocytic spots are large, round, crimson-red projections on the surface of EV which looks like blood blisters. ${ }^{29}$

The most widely used classification for GV was developed by Sarin et al, classifying GV into four distinct types, i.e., type $1 \mathrm{GOV}$ (GOV1), type 2 GOV (GOV2), type 1 IGV (IGV1), and type 2 IGV (IGV2) (Table 5). GOV1 are the most common of all GV. GOV2 and IGV1 (Fig. 3) are associated with higher incidence of variceal bleeding. Mortality is higher in patients with GOV2. ${ }^{31}$ Other clas-
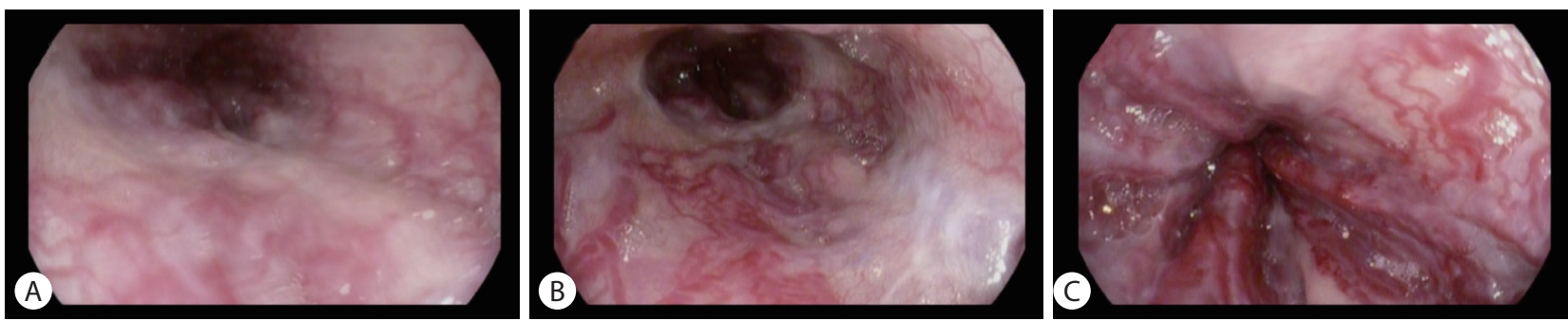

Figure 2. High-risk esophageal varices with red-color signs: (A) red wale markings, (B) cherry-red spots, and (C) hematocytic spots.

Table 5. Sarin's classification of gastric varices

\begin{tabular}{ll}
\hline GOV & \multicolumn{1}{c}{ Classification } \\
Type $1 \mathrm{GOV}$ & Gastric varices are continuous with esophageal varices \\
& Extend $2-5 \mathrm{~cm}$ below the gastroesophageal junction along the lesser curve of the stomach \\
Type $2 \mathrm{GOV}$ & $\begin{array}{l}\text { Extend beyond the gastroesophageal junction into the fundus of the stomach and along the } \\
\text { greater curve of the stomach } \\
\text { Long, nodular, and tortuous }\end{array}$ \\
IGV & Gastric varices in the absence of esophageal varices \\
Type 1 IGV/fundal varices & Located in the fundus and fall short of the cardia by a few centimeters \\
& Nodular and tortuous often with red color signs \\
Type 2 IGV/isolated ectopic varices & Located in the body, antrum, or pylorus
\end{tabular}

GOV, gastroesophageal varices; IGV, isolated gastric varices.
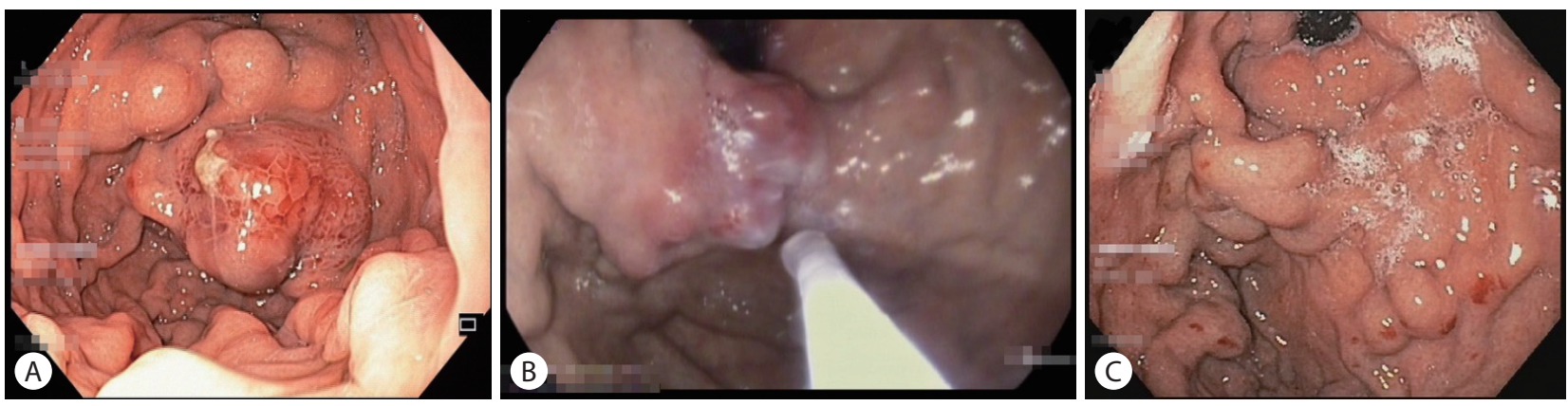

Figure 3. IGV1 (A, B) and high-risk gastric varices with red-color sign (C). IGV, isolated gastric varices. 
sifications of GV include Hoskins and Johnson's classification, Mathur's classification, and Hashizume's classification. ${ }^{18}$

Repeat EGD is recommended by the AASLD when decompensation occurs, every year for compensated LC patients with small varices on screening and ongoing liver injury, every 2 years for compensated LC patients with small varices and inactive liver injury (after viral elimination or alcohol abstinence) or no varices and ongoing liver injury, and every 3 years for compensated LC patients with no varices and inactive liver injury. ${ }^{24}$ On the other hand, EASL recommends repeat EGD every year for patients with no varices and ongoing liver injury or decompensation; APASL recommends EGD every two years for patients with no varices on screening; and KASL recommends EGD every $1-2$ years for patients with decompensated LC and 2-3 years for patients with compensated $L C$ according to severity of underlying disease. . $5,27,28^{-}$

Even though EGD is the recommended examination for screening of varices, most patients resist undergoing EGD due to its invasiveness. Non-invasive modalities have also been developed to detect the presence of varices, such as TE/Fibroscan ${ }^{\circledR}$, portal vein doppler ultrasound, and capsule endoscopy. Non-invasive methods for detection of varices (Fig. 4) warrants further studies as cut-off values for detection of varices varies among different stud- ies. ${ }^{32}$ Recently, the Baveno VI consensus reported that combining liver stiffness less than $20 \mathrm{kPa}$ and platelet count more than $150,000 / \mathrm{mm}^{3}$ can rule out high-risk varices in compensated advanced chronic liver disease patients. ${ }^{5}$ Using the Baveno $\mathrm{VI}$ criteria, a study of 1,218 patients with compensated advanced chronic liver disease showed that the varices-needing-treatment miss rate was $1.9 \%$ with a $25.7 \%$ saved endoscopy rate. However, in these patients, the optimal criteria of liver stiffness and platelet count for predicting varices-needing-treatment varied according to underlying liver disease. The study also suggested the use of liver stiffness measurement-spleen diameter to platelet index (cut-off 1.47) as predictor of varices-needing-treatment as it is not affected by underlying liver disease. ${ }^{33}$

Endoscopic ultrasound (EUS) is another minimally invasive modality that has been developed to screen for varices. Studies regarding the role of EUS in management of varices showed that though EUS was inferior to EGD in detecting and classifying $E V$, it was superior to EGD in detecting GV, paraesophageal varices, and paragastric varices. This is because EUS has the advantage to observe veins located under or outside the wall of the esophagus and stomach. Paraesophageal and paragastric varices are correlated with higher portal pressure and are risk factors for $A \vee B .^{34}$

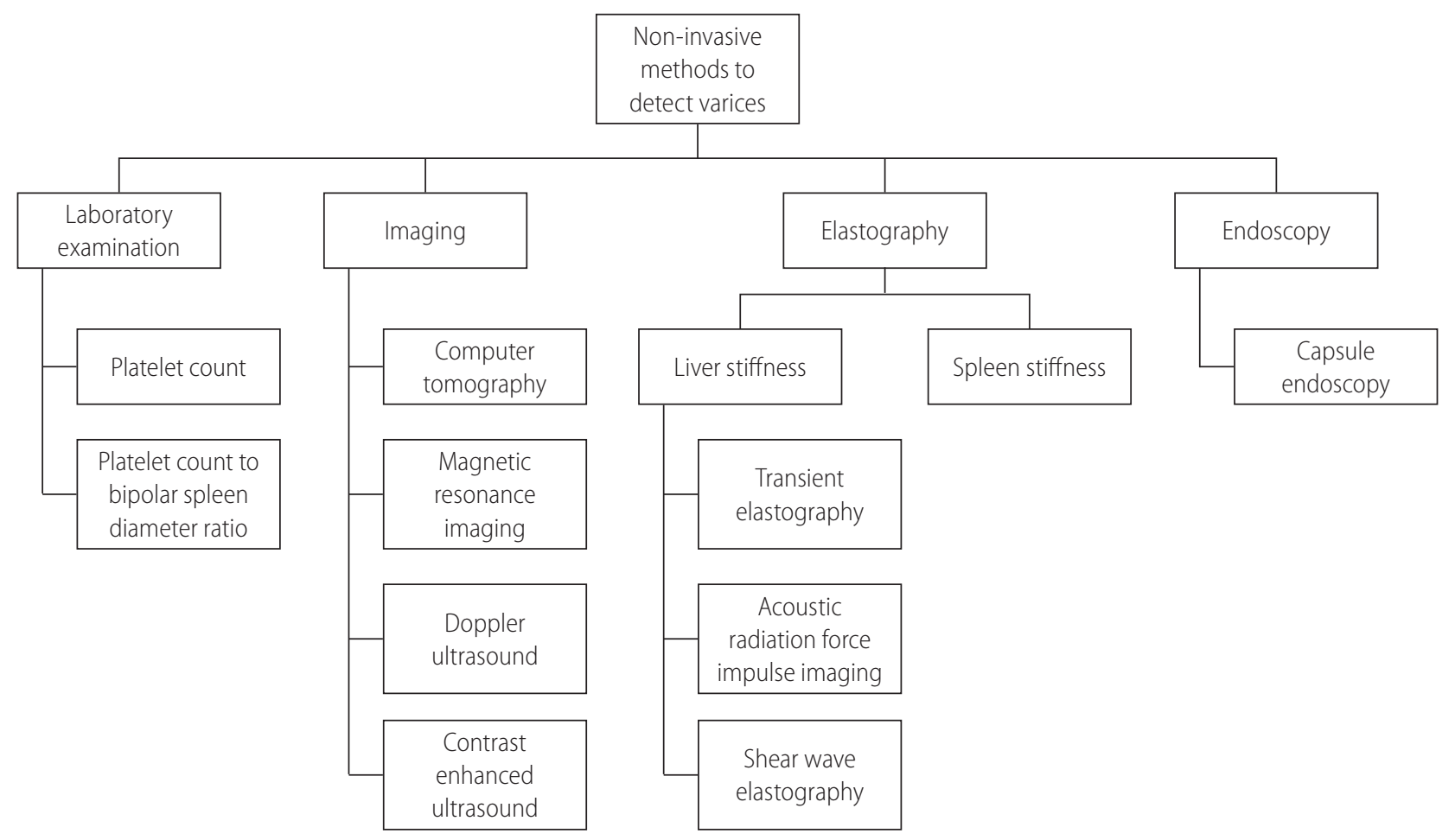

Figure 4. Non-invasive methods for detection of esophagogastric varices. ${ }^{32}$ 


\section{Pre-primary prophylaxis of EV}

Pre-primary prophylaxis is a term referring to therapies given to prevent development of varices. ${ }^{25}$ AASLD recommends elimination of etiologic agent such as hepatitis virus, alcohol, or iron as the mainstay of therapy and does not recommend the use of non-selective beta blocker (NSBB) for pre-primary prophylaxis. APASL and KASL echo these recommendations while EASL has made no recommendations regarding pre-primary prophylaxis..$^{24,25,27,28}$ Recent studies show that the use of NSBB in early cirrhosis is ineffective and may be associated with increased adverse events. ${ }^{35}$

\section{Early primary prophylaxis of EV}

Early primary prophylaxis refers to therapies aimed at preventing enlargement of varices from small to large or variceal bleed in small varices. ${ }^{25}$ All the aforementioned guidelines and guidance recommend NSBB for high-risk small EV to prevent first variceal bleed. However, only APASL and KASL recommend NSBB for lowrisk EV to prevent progression of small to large varices. KASL also recommends carvedilol for low-risk EV. ${ }^{24,25,27,28}$ However, Groszmann et al. ${ }^{36}$ found that there was no significant difference between patients receiving timolol versus patients receiving placebo in the development of varices. Furthermore, adverse events in patients receiving timolol were significantly higher than patients receiving placebo ( $18 \%$ vs. $6 \%, P=0.006) .{ }^{36}$ A prospective, singleblind randomized controlled trial (RCT) by Sarin et al. ${ }^{37}$ of 150 subjects also failed to show that propranolol was able to prevent the growth of small EV when compared to placebo. In this study, the 2-year risk of variceal growth was $11 \%$ in the propranolol group and $16 \%$ in the placebo group $(P=0.786) .{ }^{37}$ Similarly, two meta-analysis of four studies involving 730 patients with no or small varices and three studies involving 438 patients with small varices, respectively, found that incidence of developing large varices and first variceal bleeding were similar between the NSBB group and the placebo group. Both studies also showed that incidence of adverse effects were significantly higher in the NSBB group compared to the placebo group. ${ }^{38,39}$ Meanwhile, an RCT of 140 patients by Bhardwaj et al. ${ }^{40}$ showed that carvedilol is safe and effective in delaying the progression of small to large EV. Compared to placebo, carvedilol was associated with a significantly higher proportion of patients not progressing to large EV (79.4\% vs. $61.4 \%, P=0.04)$. Carvedilol also significantly slowed the progression of small to large $\mathrm{EV}$ when compared with placebo (mean time of progression was 18.7 months in the placebo group and 20.8 months in the carvedilol group, $P=0.04){ }^{40}$

\section{Primary prophylaxis of EGV}

Primary prophylaxis refers to therapies aimed to prevent first variceal bleed in medium-large $\mathrm{EV}$ or $\mathrm{GV} .{ }^{25} \mathrm{AASLD}$ recommends NSBB, carvedilol, or endoscopic variceal ligation (EVL) and does not recommend combination therapy of NSBB and EVL for primary prevention of EV. ${ }^{24}$ EASL recommends NSBB or EVL for primary prophylaxis of EV (with preference to NSBB as it can lower portal pressure). $\mathrm{EVL}$ is the preferred therapy for patients intolerant to NSBB or with contraindications to NSBB. ${ }^{27}$ APASL also recommends NSBB with HVPG monitoring or EVL for primary prophylaxis of EV. EVL should be offered to patients who are intolerant or nonresponsive to NSBB. ${ }^{25}$ KASL recommends NSBB, carvedilol, $E V L$, or combination of NSBB and EVL for primary prophylaxis of EV. ${ }^{28}$ Propranolol (20-40 mg twice a day) or nadolol (20-40 mg once a day) can be given with dose adjustments every $2-3$ days until treatment goal (resting heart rate of 55-60 beats per minute) is achieved. The maximum dose for propranolol is $320 \mathrm{mg}$ per day for patients without ascites and $160 \mathrm{mg}$ per day for patients with ascites. The maximum dose for nadolol is $160 \mathrm{mg}$ per day for patients without ascites and $80 \mathrm{mg}$ per day for patients with ascites. On the other hand, dose for carvedilol is easier to adjust because it is not guided by heart rate, starting with $6.25 \mathrm{mg}$ once a day or $3.125 \mathrm{mg}$ twice a day and later increased to $6.25 \mathrm{mg}$ twice a day after 3 days. The maximum dose of carvedilol is $12.5 \mathrm{mg}$ per day. Systolic blood pressure should not be lower than 90 $\mathrm{mmHg}$ with NSBB or carvedilol therapy. ${ }^{24,28}$ Studies on NSBB have been conflicting with earlier studies supporting NSBB use and more recent studies suggesting potential harm from NSBB usage. Adverse effects of NSBB therapy may be cardiac related as a result of decreased cardiac output and chronotropy associated with beta-1 antagonism (exacerbation of heart failure, symptomatic bradycardia, heart block, or fatigue) or non-cardiac related due to non-selective beta-adrenergic blockade (bronchospasm, exacerbation of peripheral artery disease, or sexual dysfunction). NSBB should be tapered and discontinued in decompensated LC patients with refractory ascites. In these group of patients, the use of NSBB may reduce survival of patients due to its negative impact on cardiac output which decreases perfusion to vital organs. Furthermore, NSBB should be used with caution in patients with poor adherence to follow-up or poor medical compliance. ${ }^{35}$ Despite this, a recently published systematic review, with network meta-analysis of 32 RCTs involving 3,362 LC patients with large 
EV and no prior history of bleeding, suggests that NSBB is the preferred initial approach for primary prophylaxis of EV bleeding. This meta-analysis found that NSBB monotherapy decreases mortality (odds ratio [OR], 0.70; 95\% confidence interval $[\mathrm{Cl}], 0.49-$ $1.00)$ and prevents first variceal bleed $(\mathrm{OR}, 0.64 ; 95 \% \mathrm{Cl}, 0.38-$ 1.07). Combination therapy of NSBB and EVL also decreased mortality $(O R, 0.49 ; 95 \% \mathrm{Cl}, 0.23-1.02)$ and prevented first variceal bleed $(\mathrm{OR}, 0.34 ; 95 \% \mathrm{Cl}, 0.14-0.86)$ but carried a higher risk of serious adverse events. Carvedilol and EVL monotherapy were also effective in preventing first variceal bleed, OR $0.21(95 \% \mathrm{Cl}$, $0.08-0.56)$ and $0.33(95 \% \mathrm{Cl}, 0.19-0.55)$, respectively, but did not reduce mortality. ${ }^{41}$ Another systematic review and meta-analysis showed that carvedilol, a potent beta-blocker with intrinsic anti-alpha-1 receptor activity, is as effective as propranolol (3 RCTs; relative risk [RR], $0.76 ; 95 \% \mathrm{Cl}, 0.27-2.14$ ) and EVL (4 RCTs; RR, $0.74 ; 95 \% \mathrm{Cl}, 0.37-1.49$ ) for primary prophylaxis of $E V$ bleeding. This study also showed that there was no difference in the incidence of all-cause mortality between carvedilol and EVL or propranolol. ${ }^{42}$ Hence, carvedilol is an effective and safe alternative for primary prophylaxis of EV bleeding. Evidence also recommends EVL as an effective alternative. A meta-analysis of 19 RCTs including 1,438 patients comparing NSBB and EVL in primary prophylaxis of EV bleeding found that overall bleeding rates were significantly lower for the EVL group $(O R, 2.06 ; 95 \% \mathrm{Cl}$, 1.55-2.73) compared to the NSBB group. However, after inclusion of high-quality trials, no difference was found in regard to bleeding rate and mortality between the two groups. EVL was associated with more fatal adverse events. ${ }^{43}$ For primary prophylaxis,

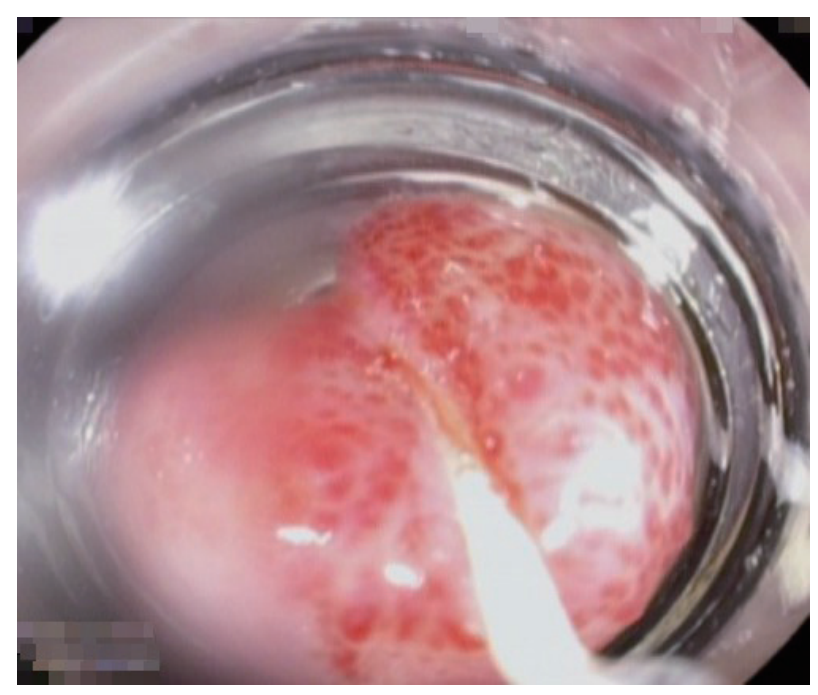

Figure 5. Endoscopic variceal band ligation.
EVL (Fig. 5) should be done every 2-8 weeks until variceal eradication is achieved. ${ }^{24}$

Until now there is still a lack of studies on primary prophylaxis of GV bleeding. As GOV1 is closely related to EV, primary prophylaxis of GOV1 follows recommendations for EV. Meanwhile, for primary prophylaxis of GOV2 and IGV1, AASLD and EASL recommend the use of NSBB. ${ }^{24,27}$ APASL also recommends NSBB for primary prophylaxis of GV bleeding in high-risk GOV2 and IGV1 (more than $5 \mathrm{~mm}$ in diameter, with red-color signs, and in CP class B or C LC). For APASL, balloon-occluded retrograde transvenous obliteration (BRTO) may also be considered in centres able to perform this procedure even though this procedure may increase size of $\mathrm{EV} .{ }^{25} \mathrm{KASL}$ is the only one that does not recommend NSBB use for primary prophylaxis of GOV2 or IGV1. Instead, KASL recommends BRTO, vascular plug-assisted retrograde transvenous obliteration, or endoscopic variceal obturation (EVO) ${ }^{28} \mathrm{EVO}$ is an endoscopic procedure involving the injection of tissue adhesives such as N-butyl-2-cyanoacrylate into GV. ${ }^{12}$ Mishra et al showed that EVO is more effective than NSBB or no therapy in preventing first variceal bleeding in $89 \mathrm{LC}$ patients with GOV2 or IGV1. Size of GV $>20 \mathrm{~mm}$, Model for End-Stage Liver Disease score $\geq 17$, and the presence of gastropathy are factors predicting high risk of first bleeding from GV. Primary prophylaxis should be given in patients with these factors. ${ }^{44}$

\section{AVB}

$A V B$, defined as hematemesis and/or ongoing melena within the last 24 hours in a known or suspected case of $\mathrm{PH}$, is a medical emergency in LC patients responsible for about one-third of all cirrhosis-related deaths and $70 \%$ of all upper gastrointestinal bleeding episodes in patients with $\mathrm{PH}^{26,45}$ To lower mortality, AVB should be managed promptly by a multidisciplinary team of experienced medical staff. Modalities of AVB management include initial resuscitation, pharmacotherapy, endoscopic therapy, and rescue therapy (Fig. 6). Treatment of bleeding from EV and GV is similar except for endoscopic therapy. The immediate goal of therapy is to control bleeding and prevent rebleeding. ${ }^{45}$ Close monitoring of patients is recommended by EASL. ${ }^{27}$

Initial resuscitation of patients with variceal bleeding follows the airway, breathing, and circulation scheme. APASL recommends airway elective intubation in patients with severe uncontrolled bleeding, hepatic encephalopathy grade III and IV, aspiration pneumonia, and difficulty in maintaining oxygen saturation above $90 \% .{ }^{26}$ All patients should have intravenous access for fluid 




Figure 6. Management of patients with acute variceal bleeding. AVB, acute variceal bleeding; EGD, esophagogastroduodenoscopy; EV, esophageal varices; GOV1, type 1 gastroesophageal varices; GOV2, type 2 gastroesophageal varices; IGV, isolated gastric varices; EVL, endoscopic variceal ligation; EVO, endoscopic variceal obturation; TIPS, transjugular intrahepatic portosystemic shunt; BRTO, balloon-occluded retrograde transvenous obliteration.

volume resuscitation and transfusion of blood products to restore and maintain hemodynamic stability. EASL recommends colloids and/or crystalloid for volume resuscitation, meanwhile APASL recommends colloids for resuscitation. Target of volume resuscitation is maintenance of systolic blood pressure above $100 \mathrm{mmHg}$, heart rate below 100 beat per minute, central venous pressure 1-5 $\mathrm{mmHg}$, and diuresis of $40 \mathrm{~mL}$ per hour. ${ }^{26,27}$ All four guidelines/ guidance recommend conservative or restrictive packed red blood cell transfusion suggesting a transfusion threshold of $7 \mathrm{~g} / \mathrm{dL}$ and a transfusion target of 7-9 g/dL. $24,26-28$ Over-transfusion can increase portal pressure and result in rebleeding. Restrictive transfusion is associated with lower risk of mortality (RR, $0.65 ; 95 \%$ $\mathrm{Cl}, 0.44-0.97 ; P=0.03)$ and rebleeding $(\mathrm{RR}, 0.58 ; 95 \% \mathrm{Cl}, 0.40-$ $0.84 ; P=0.004)$ compared to liberal transfusion. ${ }^{46}$

Antibiotic prophylaxis and vasoconstrictors should be adminis- tered in all $\mathrm{LC}$ patients with AVB. Short term antibiotic prophylaxis (5-7 days) is recommended by all four guidelines/guidance. Intravenous ceftriaxone is the antibiotic of choice. For EASL, intravenous ceftriaxone is indicated in decompensated cirrhosis, patients on quinolone, and in hospitals with high-prevalence of resistance, while oral quinolones is indicated in the remaining patients. ${ }^{24,26-28}$ Antibiotic prophylaxis significantly reduces bacterial infections, mortality, rebleeding, and hospitalization length when compared to no antibiotic prophylaxis. ${ }^{47}$ Vasoconstrictors should be administered as soon as AVB is suspected and continued until $3-5$ days after endoscopic therapy as recommended by all four hepatology societies. ${ }^{24,26-28} \mathrm{~A}$ recent review, however, suggests that vasoconstrictor therapy can be shortened to 24 hours or discontinued soon after successful control of bleeding by means of $E V L$; this warrants further studies. ${ }^{48}$ Terlipressin, somatostatin, and octreo- 
Cosmas Rinaldi Adithya Lesmana, et al.

tide are vasoconstrictors that can be chosen for treatment of AVB. APASL recommends terlipressin as first-line option due to studies which showed terlipressin to be the only vasoconstrictor that reduces mortality when compared to placebo. ${ }^{26,49}$ However, a more recent study showed that there was no significant difference between terlipressin, somatostatin, and octreotide in the control of $A V B$, rebleeding rates, and mortality. ${ }^{50}$ Another meta-analysis showed that terlipressin had a significantly higher risk of complications when compared to somatostatin and a significantly inferior control of bleeding within 24 hours when compared to octreotide. ${ }^{51}$ Recommended dosage of vasoconstrictors are as follows: terlipressin 2 mg every 4 hours intravenously, somatostatin 250 mcg every hour intravenously, and octreotide 50 mcg every hour intravenously. ${ }^{28}$

EGD should be performed as soon as possible (within 12 hours according to AASLD and EASL; within 6 hours according to APASL) to confirm a variceal bleed and perform endoscopic therapy. ${ }^{24,26,27}$ AVB is confirmed when active bleeding from a varix (spurting or oozing) or sign of recent bleeding (white nipple sign or overlying clot) is seen. ${ }^{26}$ AASLD, EASL, APASL, and KASL agree that EVL is the endoscopic therapy of choice for acute EV bleeding. Meanwhile, EVL and/or EVO are the endoscopic therapy of choice for bleeding from GOV1 and EVO for bleeding from GOV2 or IGV1. ${ }^{24,26-28}$ EVO has been considered as the preferred method for managing acute bleeding from GOV2 and IGV1 when compared to endoscopic sclerotherapy injection or EVL. ${ }^{52} \mathrm{~A}$ prospective study showed that even though EVL and cyanoacrylate injection have the same efficacy in controlling active bleeding, rebleeding rate is significantly lower in patients receiving cyanoacrylate injection $(P=0.044) .{ }^{53}$ Apart from endoscopic therapy, transjugular intrahepatic portosystemic shunt (TIPS) and BRTO (also modified BRTO techniques such as vascular plug-assisted retrograde transvenous obliteration and balloon-occluded antegrade transvenous obliteration) are recommended therapies for controlling bleeding from GOV2 or IGV1. Only AASLD recommends TIPS as treatment of choice over EVO; meanwhile EASL, APASL, and KASL recommend that EVO be considered first before TIPS or transvenous obliteration. ${ }^{24,26-28}$ A retrospective cohort analysis of 169 patients with GOV2 showed that TIPS and EVO are equally effective in bleeding control and treatment outcomes, which include re-bleeding within 30 days, median length of stay in the hospital, and in-hospital mortality. ${ }^{54}$ Due to lack of data, treatment choice for fundal varices should be individualized.

Rescue therapy is therapy given when bleeding control is inadequate or bleeding recurs despite receiving standard pharmacologi- cal and endoscopic therapy. Up to $10-20 \%$ of patients with bleeding from EV experienced persistent bleeding or early rebleeding. AASLD, EASL, APASL, and KASL recommend TIPS as the rescue therapy of choice for these patients. Early TIPS is also recommended by these guidelines in selected patients. AASLD suggests early TIPS (within 72 hours after EVL) for patients of CP class $C$ or patient of CP class B with active bleeding on EGD. EASL suggests early TIPS (within 24-72 hours) in patients of CP class C with score less than 14. APASL suggests early TIPS (within 24 hours of bleeding) in patients with HVPG more than $20 \mathrm{mmHg}$. Meanwhile, KASL also suggests early TIPS in patients with highrisk of rebleeding but have no recommendations on timing or criteria of high-risk patients. ${ }^{24,26-28}$ One hundred thirty-two patients with CP class B or C less than 14 and AVB were randomly assigned to receive early TIPS (within 72 hours after endoscopy) or standard treatment (vasoconstrictor up to 5 days followed by propranolol plus EVL with TIPS as rescue therapy). Transplant-free survival was significantly higher in the early TIPS group than in the control group (hazard ratio [HR], 0.50; 95\% Cl, 0.25-0.98; $P=0.04) .{ }^{55}$ There is currently no recommendation for rescue therapy for GV bleeding; however, TIPS and BRTO may be considered if EVO fails to control bleeding.

In uncontrolled bleeding, a temporary bridge therapy may be given before definitive treatment. Balloon tamponade is the bridge therapy recommended by all four guidelines/guidance. Balloon tamponade, with a Sengstaken Blakemore tube compressing varices at the esophagogastric junction, enables temporary control of bleeding in up to $80 \%$ of patients but should not exceed 24 hours. Endoscopically placed self-expanding metal stents can be used as an alternative to balloon tamponade in cases of uncontrolled bleeding. Endoscopic metallic stent placement tamponade varices to stop bleeding and can be left until 2 weeks. ${ }^{24,26-28} \mathrm{~A}$ meta-analysis of 12 studies show that pooled clinical success rate of self-expanding metal stents in achieving hemostasis was $96 \%$ with only $36 \%$ of patients experiencing adverse events (rebleeding after 48 hours, ulceration, or stent migration). ${ }^{56}$

New modalities have also been studied for bleeding control in $A V B$, such as BRTO, endoscopic hemospray/hemostatic powder, and EUS-assisted therapy. BRTO is a procedure where the left renal vein is cannulated through the jugular or femoral vein followed by balloon occlusion and slow infusion of sclerosant to obliterate gastro-renal or splenorenal collateral of fundal GV. A retrospective data analysis showed that technical success of BRTO was achieved in $96.7 \%$ of patients with GV bleeding, even though only $72.8 \%$ achieved GV size reduction and only $52.3 \%$ 
achieved GV eradication. ${ }^{57}$ BRTO did not have a negative impact on prognosis in CP class $\mathrm{C}$ and end-stage $\mathrm{LC}$ patients. ${ }^{58}$ In a recent meta-analysis, BRTO was also found to be superior to TIPS for fundal GV in terms of higher overall survival rate and lower rebleeding rates. ${ }^{59}$ Endoscopic hemospray is another innovation in the management of AVB. TC-325 is a hemostatic powder which adheres to bleeding site and achieves rapid hemostasis when it came into contact with blood or tissue in the gastrointestinal tract. The advantage of this modality is that a precise target location is not needed for administration of spray. Early endoscopic hemospray application within 2 hours followed by subsequent endoscopic therapy the next day significantly improves hemostasis and survival at 6 weeks when compared with endoscopic therapy only and may be considered in centres with minimal endoscopic expertise. ${ }^{60,61}$ Recently, EUS has also been used to assist endoscopic therapy, such as injection of sclerosant into EV or injection of glue into GV. The advantage of using EUS are detailed evaluation of varices and paraesophageal varices for treatment prediction and precise real-time confirmation of drug injection into variceal lumen, especially IGV. ${ }^{34}$ EUS-guided coil embolization can also be done for GV. Embolization coils can be deployed directly over the varix after puncturing GV with a 19-gauge EUS needle. A successful case of GV treated with EUS-guided coil embolization and injection of absorbable gelatin sponge demonstrated complete obliteration of GV 4 months after procedure. ${ }^{62}$

\section{Secondary prophylaxis of EGV}

Secondary prophylaxis are therapies given to prevent rebleeding in patients who have recovered from an episode of AVB. These patients have a high rebleeding risk up to $60 \%$ in the first year. ${ }^{24,27}$ Rebleeding can be defined as new hematemesis or melena occurring 48 hours after the first hematemesis or melena. It can be further classified as very early rebleeding (48-120 hours), early rebleeding (6-42 days), and late rebleeding ( $>42$ days). High HVPG greater than $20 \mathrm{mmHg}$ (Fig. 1), alcoholic liver disease, and infection are predictors of early rebleeding. Fundal GV are associated with higher rates of rebleeding. ${ }^{26}$ To decrease mortality and increase survival, secondary prophylaxis should be instituted in all patients recovering from AVB.

AASLD, EASL, and KASL recommend combination therapy of NSBB and EVL for patients after EV bleeding. ${ }^{24,27,28}$ Combination therapy is more effective than NSBB or EVL alone, ${ }^{63}$ however, if difficult, NSBB or EVL alone is recommended by KASL. ${ }^{28}$ Dosing and goal of NSBB therapy follows that of primary prophylaxis. EVL should be done every 1-4 weeks (as opposed to every 2-8 weeks in primary prophylaxis) until eradication of varices. ${ }^{24} \mathrm{~A}$ meta-analysis of five studies found that combination therapy of EVL plus NSBB and/or isosorbide mononitrate has the same efficacy as NSBB and isosorbide mononitrate alone in prevention of rebleeding. Hence, isosorbide mononitrate may be added as an alternative when EVL is not possible to perform. ${ }^{64}$ Patients receiving early TIPS should undergo ultrasound to assess TIPS patency every 6 months and do not require specific therapy. TIPS is recommended as rescue therapy by AASLD and KASL and as an alternative in cases of NSBB intolerance by EASL. ${ }^{24,27,28}$ TIPS was superior to combination therapy of NSBB and EVL for reduction of variceal rebleeding but did not improve survival of patients and was associated with higher incidence of hepatic encephalopathy. ${ }^{65,66}$

Risk of rebleeding among patients treated with cyanoacrylate injection for GV varies from $15-72 \%{ }^{67,68}$ After recovery from GOV1 bleeding, AASLD recommends combination therapy of NSBB and EVL or EVO as secondary prophylaxis. ${ }^{24}$ Meanwhile KASL recommends repeated EVO or EVL as secondary prophylaxis. ${ }^{28}$ As there is a lack of study in GOV1 patients, secondary prophylaxis of GOV1 is in principle similar to that of EV. GOV1 patients treated with EVO experienced significantly lower rates of GV recurrence $(P=0.007)$ and variceal bleeding $(P=0.034)$ when compared with GOV2 patients treated with EVO. ${ }^{69}$ In patients who have recovered from GOV2 or IGV1 bleeding, AASLD recommends TIPS or BRTO as secondary prophylaxis, while KASL recommends EVO or BRTO ${ }^{24,28} \mathrm{NSBBs}$ are not recommended as they are not effective in prevention of rebleeding from fundal GV. An RCT of 67 patients with GOV2 or IGV1 showed that even though reduction in HVPG was only seen in the NSBB group, risk of rebleeding and mortality rate after a median follow-up of 26 months was significantly lower in the EVO group than the NSBB group ( $15 \%$ vs. $55 \%, P=0.004$ and $3 \%$ vs. $25 \%, P=0.026$, respectively). ${ }^{70}$ However, when compared with TIPS, incidence of rebleeding from GV was significantly higher in the EVO group (38\% vs. $11 \%, P=0.014)$. Meanwhile, variceal obliteration was significantly higher in the EVO group ( $51 \%$ vs. $20 \%, P<0.02$ ). TIPS was more effective than EVO in preventing rebleeding from GV. ${ }^{71}$ Studies comparing BRTO with TIPS or EVO for secondary prophylaxis have yet to be published.

\section{MANAGING EGV IN CLINICAL PRACTICE}

Based on studies of $L C$ patients in the largest referral public 
Cosmas Rinaldi Adithya Lesmana, et al.

hospital in Indonesia, Dr. Cipto Mangunkusumo National General Hospital, hepatitis B virus infection is still the most common etiology of LC in the Indonesian population, followed by hepatitis C virus infection. EGD was performed in approximately 300 cirrhotic patients each year in our hospital. The majority of patients undergoing EGD for screening had CP class A. Indications for EGD evaluation are screening for varices, evaluation of previous $E V L$, and AVB. ${ }^{72-74}$

Challenges we face in managing EGV in Indonesia include lack of endoscopic facility/expertise and patients' reluctance to undergo EGD and/or HVPG due to its invasiveness. In resource-limited settings, non-invasive modalities to assess portal pressure or detect varices, such as TE, are also not available. Platelet count and bipolar spleen diameter measurement may be done to detect high-risk varices in our population. In compensated LC patients without history of $A V B$, low platelet count $\left(\leq 100,000 / \mathrm{mm}^{3}\right)$, increased bipolar spleen diameter ( $\geq 135 \mathrm{~mm}$ ), and platelet count/ bipolar spleen diameter ratio $\leq 847$ were associated with highrisk varices based on univariate analysis. Only platelet count/bipolar spleen diameter ratio $\leq 847$ was associated with high-risk varices based on multivariate analysis. The use of platelet count/ bipolar spleen diameter ratio for detection of high-risk varices in compensated cirrhotic patients had area under the receiver operating characteristic curve of 0.77 , sensitivity of $90.6 \%$, and specificity of $58.3 \%$. $^{74}$

A recent study by Lesmana et al. ${ }^{72}$ showed that EV was found in $73.20 \%$ of LC patients; meanwhile GOV and IGV were only found in $18.30 \%$ and $8.49 \%$, respectively. Although GV is less prevalent than EV, patients with GV, particularly GOV, were associated with a greater risk for AVB. Multivariate analysis showed that CP class $\mathrm{C}$ and the presence of GOV are risk factors associated with 1-year variceal bleeding in cirrhotic patients $(\mathrm{HR}, 12.49$; 95\% Cl, 4.9531.54, $P=0.001$ and $\mathrm{HR}, 2.95 ; 95 \% \mathrm{Cl}, 1.40-6.19 ; P=0.004$, respectively). CP class $C$ was the only one found to be a risk factor for 1-year mortality in cirrhotic patients through multivariate analysis (HR, 26.77; 95\% Cl, 6.01-119.34; $P=0.001) .{ }^{72}$ Consistent with the previous study, the presence of high-risk varices was $80.60 \%$ in patients with CP class C, significantly higher compared to patients with CP class A (47.50\%). EVL was done in $46.7 \%$ of patients; $33.6 \%$ of EVL during screening of varices, $39 \%$ after evaluation of previous EVL, and $27.4 \%$ due to $A V B$. In patients presenting with $A V B, 32.7 \%$ had previous EVL, $13.5 \%$ were consuming NSBB, meanwhile $53.8 \%$ had no history of EVL or NSBB consumption reinforcing the importance of primary prophylaxis in the management of variceal bleeding. ${ }^{73}$
Our studies suggest that halting the progress of LC by managing underlying liver disease is important in decreasing mortality rate of CSPH patients. Even though new modalities and techniques have been developed to manage varices and AVB, such as contrast-enhanced ultrasound and EUS, the development of varices should be seen as a continuum from underlying chronic liver disease to LC, PH, and consequently CSPH. Hence, management of underlying liver disease should not be overlooked when managing patients with $\mathrm{EGV}$.

\section{CONCLUSION}

EV and GV are important complications of LC due to its high mortality when AVB occurs. PH and hyperdynamic circulation in cirrhotic patients are underlying mechanisms of variceal development. HVPG is currently the gold standard for measurement of portal pressure. Meanwhile, EGD is currently the gold standard for detection of varices in patients with LC. Non-invasive methods to assess portal pressure and detect varices have been developed. In resource-limited settings, platelet count, bipolar spleen diameter, and liver stiffness measurement with TE/Fibroscan ${ }^{\circledR}$ may be useful in evaluating patients with LC. NSBBs are currently recommended to prevent AVB. However, NSBBs should be used with caution in decompensated cirrhotic patients. The presence of GOV should not be overlooked as they are associated with higher risk of 1-year variceal bleeding. Pharmacological therapy, endoscopic therapy (EVL or EVO), radiologic interventions (TIPS, BRTO, and modified BRTO techniques), and other innovative interventions are available for the prevention and management of variceal bleeding. Further studies should be done to validate the available non-invasive methods for measuring portal pressure and detecting varices and to discover more effective therapies to prevent variceal development and to manage AVB. The management of underlying liver disease might be the most important and should not be overlooked when managing patients with EGV.

\section{Authors' contribution}

CRAL provided the writing idea; CRAL and MR wrote the manuscript; CRAL, MR and RAG corrected the manuscript.

\section{Conflicts of Interest}

The authors have no conflicts to disclose. 


\section{REFERENCES}

1. Pinzani M, Rosselli M, Zuckermann M. Liver cirrhosis. Best Pract Res Clin Gastroenterol 2011;25:281-290.

2. Mokdad AA, Lopez AD, Shahraz S, Lozano R, Mokdad AH, Stanaway J, et al. Liver cirrhosis mortality in 187 countries between 1980 and 2010: a systematic analysis. BMC Med 2014;12:145.

3. GBD 2017 Cirrhosis Collaborators. The global, regional, and national burden of cirrhosis by cause in 195 countries and territories, 19902017: a systematic analysis for the Global Burden of Disease Study 2017. Lancet Gastroenterol Hepatol 2020;5:245-266.

4. D'Amico G, Garcia-Tsao G, Pagliaro L. Natural history and prognostic indicators of survival in cirrhosis: a systematic review of 118 studies. J Hepatol 2006;44:217-231.

5. de Franchis R; Baveno VI Faculty. Expanding consensus in portal hypertension: report of Baveno VI Consensus Workshop: stratifying risk and individualizing care for portal hypertension. J Hepatol 2015;63:743-752.

6. Samonakis DN, Koulentaki M, Coucoutsi C, Augoustaki A, Baritaki C, Digenakis E, et al. Clinical outcomes of compensated and decompensated cirrhosis: a long term study. World J Hepatol 2014;6:504512.

7. Pellicoro A, Ramachandran P, Iredale JP, Fallowfield JA. Liver fibrosis and repair: immune regulation of wound healing in a solid organ. Nat Rev Immunol 2014;14:181-194.

8. Elpek GÖ. Angiogenesis and liver fibrosis. World J Hepatol 2015;7: 377-391.

9. Iwakiri Y. Pathophysiology of portal hypertension. Clin Liver Dis 2014;18:281-291.

10. Miñano C, Garcia-Tsao G. Clinical pharmacology of portal hypertension. Gastroenterol Clin North Am 2010;39:681-695.

11. Procopet $B$, Berzigotti A. Diagnosis of cirrhosis and portal hypertension: imaging, non-invasive markers of fibrosis and liver biopsy. Gastroenterol Rep (Oxf) 2017;5:79-89.

12. Suk KT, Baik SK, Yoon JH, Cheong JY, Paik YH, Lee CH, et al. Revision and update on clinical practice guideline for liver cirrhosis. Korean J Hepatol 2012;18:1-21.

13. Bolognesi M, Di Pascoli M, Sacerdoti D. Clinical role of non-invasive assessment of portal hypertension. World J Gastroenterol 2017;23:110.

14. Kim MY, Suk KT, Baik SK, Kim HA, Kim YJ, Cha SH, et al. Hepatic vein arrival time as assessed by contrast-enhanced ultrasonography is useful for the assessment of portal hypertension in compensated cirrhosis. Hepatology 2012;56:1053-1062.

15. Bureau C, Metivier S, Peron JM, Selves J, Robic MA, Gourraud PA, et al. Transient elastography accurately predicts presence of significant portal hypertension in patients with chronic liver disease. Aliment Pharmacol Ther 2008;27:1261-1268.
16. Maruyama H, Yokosuka O. Pathophysiology of portal hypertension and esophageal varices. Int J Hepatol 2012;2012:895787.

17. Patel B, Han E, Swan K. Richard Schatzki: a familiar ring. AJR Am J Roentgenol 2013;201:W678-W682.

18. Abby Philips C, Sahney A. Oesophageal and gastric varices: historical aspects, classification and grading: everything in one place. Gastroenterol Rep (Oxf) 2016;4:186-195.

19. Garcia-Tsao G, Sanyal AJ, Grace ND, Carey W; Practice Guidelines Committee of the American Association for the Study of Liver Diseases; Practice Parameters Committee of the American College of Gastroenterology. Prevention and management of gastroesophageal varices and variceal hemorrhage in cirrhosis. Hepatology 2007;46:922938.

20. Philips CA, Arora A, Shetty R, Kasana V. A comprehensive review of portosystemic collaterals in cirrhosis: historical aspects, anatomy, and classifications. Int J Hepatol 2016;2016:6170243.

21. Ashkenazi E, Kovalev Y, Zuckerman E. Evaluation and treatment of esophageal varices in the cirrhotic patient. Isr Med Assoc J 2013;15: 109-115.

22. Yoshida H, Mamada Y, Taniai N, Yoshioka M, Hirakata A, Kawano $Y$, et al. Risk factors for bleeding esophagogastric varices. J Nippon Med Sch 2013;80:252-259.

23. Park EJ, Jang JY, Lee JE, Jeong SW, Lee SH, Kim SG, et al. The risk factors for bleeding of fundal varices in patients with liver cirrhosis. Gut Liver 2013;7:704-711.

24. Garcia-Tsao G, Abraldes JG, Berzigotti A, Bosch J. Portal hypertensive bleeding in cirrhosis: risk stratification, diagnosis, and management: 2016 practice guidance by the American Association for the Study of Liver Diseases. Hepatology 2017;65:310-335.

25. Sarin SK, Kumar A, Angus PW, Baijal SS, Chawla YK, Dhiman RK, et al. Primary prophylaxis of gastroesophageal variceal bleeding: consensus recommendations of the Asian Pacific Association for the Study of the Liver. Hepatol Int 2008;2:429-439.

26. Sarin SK, Kumar A, Angus PW, Baijal SS, Baik SK, Bayraktar Y, et al. Diagnosis and management of acute variceal bleeding: Asian Pacific Association for Study of the Liver recommendations. Hepatol Int 2011;5:607-624.

27. European Association for the Study of the Liver. EASL clinical practice guidelines for the management of patients with decompensated cirrhosis. J Hepatol 2018;69:406-460.

28. Korean Association for the Study of the Liver (KASL). KASL clinical practice guidelines for liver cirrhosis: varices, hepatic encephalopathy, and related complications. Clin Mol Hepatol 2020;26:83-127.

29. Tajiri T, Yoshida H, Obara K, Onji M, Kage M, Kitano S, et al. General rules for recording endoscopic findings of esophagogastric varices (2nd edition). Dig Endosc 2010;22:1-9.

30. Brick IB, Palmer ED. One thousand cases of portal cirrhosis of the liver. Implications of esophageal varices and their management. 
Cosmas Rinaldi Adithya Lesmana, et al. Liver cirrhotic complications on varices

Arch Intern Med 1964;113:501-511.

31. Sarin SK, Lahoti D, Saxena SP, Murthy NS, Makwana UK. Prevalence, classification and natural history of gastric varices: a long-term follow-up study in 568 portal hypertension patients. Hepatology 1992;16:1343-1349.

32. Karatzas A, Konstantakis C, Aggeletopoulou I, Kalogeropoulou C, Thomopoulos K, Triantos C. Non-invasive screening for esophageal varices in patients with liver cirrhosis. Ann Gastroenterol 2018;31:305-314.

33. Lee HA, Kim SU, Seo YS, Lee YS, Kang SH, Jung YK, et al. Prediction of the varices needing treatment with non-invasive tests in patients with compensated advanced chronic liver disease. Liver Int 2019;39:1071-1079.

34. Wang AJ, Li BM, Zheng XL, Shu X, Zhu X. Utility of endoscopic ultrasound in the diagnosis and management of esophagogastric varices. Endosc Ultrasound 2016;5:218-224.

35. Ge PS, Runyon BA. The changing role of beta-blocker therapy in patients with cirrhosis. J Hepatol 2014;60:643-653.

36. Groszmann RJ, Garcia-Tsao G, Bosch J, Grace ND, Burroughs AK, Planas $R$, et al. Beta-blockers to prevent gastroesophageal varices in patients with cirrhosis. N Engl J Med 2005;353:2254-2261.

37. Sarin SK, Mishra SR, Sharma P, Sharma BC, Kumar A. Early primary prophylaxis with beta-blockers does not prevent the growth of small esophageal varices in cirrhosis: a randomized controlled trial. Hepatol Int 2013;7:248-256.

38. Qi XS, Bao YX, Bai M, Xu WD, Dai JN, Guo XZ. Nonselective betablockers in cirrhotic patients with no or small varices: a metaanalysis. World J Gastroenterol 2015;21:3100-3108.

39. Kumar A, Sharma P, Anikhindi SA, Prajapati R, Agarwal R, Sharma $B$, et al. Can non-selective beta-blockers (NSBBs) prevent enlargement of small esophageal varices in patients with cirrhosis? A metaanalysis. J Clin Exp Hepatol 2017;7:275-283.

40. Bhardwaj A, Kedarisetty CK, Vashishtha C, Bhadoria AS, Jindal A, Kumar $G$, et al. Carvedilol delays the progression of small oesophageal varices in patients with cirrhosis: a randomised placebocontrolled trial. Gut 2017;66:1838-1843.

41. Sharma M, Singh S, Desai V, Shah VH, Kamath PS, Murad MH, et al. Comparison of therapies for primary prevention of esophageal variceal bleeding: a systematic review and network meta-analysis. Hepatology 2019;69:1657-1675.

42. Malandris K, Paschos P, Katsoula A, Manolopoulos A, Andreadis $P$, Sarigianni $M$, et al. Carvedilol for prevention of variceal bleeding: a systematic review and meta-analysis. Ann Gastroenterol 2019;32:287-297.

43. Funakoshi N, Duny $Y$, Valats JC, Ségalas-Largey F, Flori N, Bismuth $M$, et al. Meta-analysis: beta-blockers versus banding ligation for primary prophylaxis of esophageal variceal bleeding. Ann Hepatol 2012;11:369-383.
44. Mishra SR, Sharma BC, Kumar A, Sarin SK. Primary prophylaxis of gastric variceal bleeding comparing cyanoacrylate injection and beta-blockers: a randomized controlled trial. J Hepatol 2011;54:11611167.

45. Tayyem O, Bilal M, Samuel R, Merwat SK. Evaluation and management of variceal bleeding. Dis Mon 2018;64:312-320.

46. Odutayo A, Desborough MJ, Trivella M, Stanley AJ, Dorée C, Collins GS, et al. Restrictive versus liberal blood transfusion for gastrointestinal bleeding: a systematic review and meta-analysis of randomised controlled trials. Lancet Gastroenterol Hepatol 2017;2:354-360.

47. Chavez-Tapia NC, Barrientos-Gutierrez T, Tellez-Avila F, SoaresWeiser K, Mendez-Sanchez N, Gluud C, et al. Meta-analysis: antibiotic prophylaxis for cirrhotic patients with upper gastrointestinal bleeding - an updated cochrane review. Aliment Pharmacol Ther 2011;34:509-518.

48. Lo GH. The use of vasoconstrictors in acute variceal bleeding: how long is enough? Clin Endosc 2019;52:36-39.

49. Ioannou GN, Doust J, Rockey DC. Systematic review: terlipressin in acute oesophageal variceal haemorrhage. Aliment Pharmacol Ther 2003; 17:53-64.

50. Seo YS, Park SY, Kim MY, Kim JH, Park JY, Yim HJ, et al. Lack of difference among terlipressin, somatostatin, and octreotide in the control of acute gastroesophageal variceal hemorrhage. Hepatology 2014;60:954-963.

51. Zhou X, Tripathi D, Song T, Shao L, Han B, Zhu J, et al. Terlipressin for the treatment of acute variceal bleeding: a systematic review and meta-analysis of randomized controlled trials. Medicine (Baltimore) 2018;97:e13437.

52. Garcia-Pagán JC, Barrufet M, Cardenas A, Escorsell À. Management of gastric varices. Clin Gastroenterol Hepatol. 2014;12:919-928.

53. Tan PC, Hou MC, Lin HC, Liu TT, Lee FY, Chang FY, et al. A randomized trial of endoscopic treatment of acute gastric variceal hemorrhage: N-butyl-2-cyanoacrylate injection versus band ligation. Hepatology 2006;43:690-697.

54. Kochhar GS, Navaneethan U, Hartman J, Parungao JM, Lopez R, Gupta R, et al. Comparative study of endoscopy vs. transjugular intrahepatic portosystemic shunt in the management of gastric variceal bleeding. Gastroenterol Rep (Oxf) 2015;3:75-82.

55. Lv Y, Yang Z, Liu L, Li K, He C, Wang Z, et al. Early TIPS with covered stents versus standard treatment for acute variceal bleeding in patients with advanced cirrhosis: a randomised controlled trial. Lancet Gastroenterol Hepatol 2019;4:587-598.

56. McCarty TR, Njei B. Self-expanding metal stents for acute refractory esophageal variceal bleeding: a systematic review and metaanalysis. Dig Endosc 2016;28:539-547.

57. Jang SY, Kim GH, Park SY, Cho CM, Tak WY, Kim JH, et al. Clinical outcomes of balloon-occluded retrograde transvenous obliteration for the treatment of gastric variceal hemorrhage in Korean patients 
with liver cirrhosis: a retrospective multicenter study. Clin Mol Hepatol 2012;18:368-374.

58. Yokoyama K, Yamauchi R, Shibata K, Fukuda H, Kunimoto H, Takata $K$, et al. Endoscopic treatment or balloon-occluded retrograde transvenous obliteration is safe for patients with esophageal/gastric varices in Child-Pugh class C end-stage liver cirrhosis. Clin Mol Hepatol 2019;25:183-189.

59. Wang ZW, Liu JC, Zhao F, Zhang WG, Duan XH, Chen PF, et al. Comparison of the effects of TIPS versus BRTO on bleeding gastric varices: a meta-analysis. Can J Gastroenterol Hepatol 2020;2020: 5143013.

60. Ibrahim M, El-Mikkawy A, Abdel Hamid M, Abdalla H, Lemmers A, Mostafa I, et al. Early application of haemostatic powder added to standard management for oesophagogastric variceal bleeding: a randomised trial. Gut 2019;68:844-853.

61. Ibrahim M, El-Mikkawy A, Abdalla H, Mostafa I, Devière J. Management of acute variceal bleeding using hemostatic powder. United European Gastroenterol J 2015;3:277-283.

62. Ge PS, Bazarbashi AN, Thompson CC, Ryou M. Successful EUS-guided treatment of gastric varices with coil embolization and injection of absorbable gelatin sponge. VideoGIE 2019;4:154-156.

63. Ravipati M, Katragadda S, Swaminathan PD, Molnar J, Zarling E. Pharmacotherapy plus endoscopic intervention is more effective than pharmacotherapy or endoscopy alone in the secondary prevention of esophageal variceal bleeding: a meta-analysis of randomized, controlled trials. Gastrointest Endosc 2009;70:658-664.e5.

64. Puente A, Hernández-Gea V, Graupera I, Roque M, Colomo A, Poca $M$, et al. Drugs plus ligation to prevent rebleeding in cirrhosis: an updated systematic review. Liver Int 2014;34:823-833.

65. Holster IL, Tjwa ET, Moelker A, Wils A, Hansen BE, Vermeijden JR, et al. Covered transjugular intrahepatic portosystemic shunt versus endoscopic therapy $+\beta$-blocker for prevention of variceal rebleeding. Hepatology 2016;63:581-589.
66. Qi X, Tian Y, Zhang W, Zhao H, Han G, Guo X. Covered TIPS for secondary prophylaxis of variceal bleeding in liver cirrhosis: a systematic review and meta-analysis of randomized controlled trials. Medicine (Baltimore) 2016;95:e5680.

67. Boregowda U, Umapathy C, Halim N, Desai M, Nanjappa A, Arekapudi $S$, et al. Update on the management of gastrointestinal varices. World J Gastrointest Pharmacol Ther 2019;10:1-21.

68. Seo YS. Prevention and management of gastroesophageal varices. Clin Mol Hepatol 2018;24:20-42.

69. Lee HA, Chang JM, Goh HG, Kim TH, Lee YS, Suh SJ, et al. Prognosis of patients with gastric variceal bleeding after endoscopic variceal obturation according to the type of varices. Eur J Gastroenterol Hepatol 2019;31:211-217.

70. Mishra SR, Chander Sharma B, Kumar A, Sarin SK. Endoscopic cyanoacrylate injection versus beta-blocker for secondary prophylaxis of gastric variceal bleed: a randomised controlled trial. Gut 2010;59:729-735.

71. Lo GH, Liang HL, Chen WC, Chen MH, Lai KH, Hsu Pl, et al. A prospective, randomized controlled trial of transjugular intrahepatic portosystemic shunt versus cyanoacrylate injection in the prevention of gastric variceal rebleeding. Endoscopy 2007;39:679-685.

72. Lesmana CRA, Kalista KF, Sandra S, Hasan I, Sulaiman AS, Kurniawan J, et al. Clinical significance of isolated gastric varices in liver cirrhotic patients: a single-referral-centre retrospective cohort study. JGH Open 2019;4:511-518.

73. Kalista KF, Lesmana CRA, Sulaiman AS, Gani RA, Hasan I. Clinical profile of cirrhotic patient with esophageal varices who undergo band ligation in Cipto Mangunkusumo Hospital. J Penyakit Dalam Indones 2019;6:36-41.

74. Hasan I, Sulaiman AS, Jasirwan COM, Loho IM, Zulkifly S, Sardjan J, et al. Non-invasive predictors of moderate-large esophageal varices in compensated cirrhotic patients. Am J Gastroenterol 2019;114(Supplement):S572. 